\title{
Some aspects of calcium metabolism in malignant disease of bone
}

\author{
M. G. RINSLER ${ }^{1}$, MYFANWY GWYTHER, AND E. O. FIELD \\ From the Institute of Cancer Research, Royal Cancer Hospital, \\ Royal Marsden Hospital, London
}

SYNOPSIS The rate of calcification of new bone (accretion rate) was measured by a radioisotope technique in 20 patients with carcinoma of the breast, 14 patients with multiple myelomatosis, five patients with Paget's disease of bone, and in six patients with solitary, non-osseous tumours. The rate of bone destruction was assessed in these patients by the measurement of the rate of urinary calcium excretion.

In the patients with carcinoma of the breast and bone metastases there was a marked increase both in the accretion rate and in the urinary calcium excretion suggesting an osteoblastic response to bone destruction. An osteoblastic response was also present in the patients with multiple myelomatosis but was not correlated with the urinary calcium excretion. In patients with Paget's disease of bone, high values of accretion rate were found indicating very active new bone formation.

Episodes of hypercalcaemia and hypercalciuria may be associated with malignant tumours of widely differing types and sites of origin. These disturbances of calcium metabolism are common in patients with carcinoma of the breast, particularly in those with bone metastases. Similar disturbances associated with bone destruction are observed in many patients with multiple myelomatosis (Gutman, Tyson, and Gutman, 1936; Woodard, 1953).

It has been shown that during these episodes patients are in negative calcium balance and that the hypercalcaemia is not due to excessive absorption of calcium from the gut (Laszlo, Schulman, Bellin, Gottesman, and Schilling, 1952). Studies of the osteoblastic response to the destruction of bone in these patients have depended on the indirect evidence of the levels of alkaline phosphatase in the plasma, and it has been assumed that the increased levels of this enzyme observed in patients with metastatic tumours of bone have reflected, in the absence of obvious liver damage or metastases, increased new bone formation. Conversely, the normal or low levels of plasma alkaline phosphatase observed in patients with multiple myelomatosis have been interpreted as evidence of a failure of compensatory growth of new bone in the face of destruction by myeloma tissue (Woodard, 1953; Gutman et al., 1936).

'Present address: Group Laboratory, St. Stephen's Hospital, London, S.W.10.

Received for publication 20 April 1964.
The availability in recent years of the isotopes ${ }^{45} \mathrm{Ca},{ }^{47} \mathrm{Ca}$, and ${ }^{85} \mathrm{Ca}$ has enabled a more detailed study to be made of the turnover of calcium in the body. Short-term studies of the retention of calcium in the body are of some clinical value but they do not give information concerning the way in which the body utilizes the retained calcium (Spencer, Laszlo, and Brothers, 1957). Methods based on the measurement of isotope clearance rates have indicated that a proportion of the calcium that leaves the extracellular fluid compartment does so by routes other than those of excretion. The rate of loss of this fraction of the extracellular fluid calcium has been assumed to be a measure of the rate of calcification of newly formed bone and has been termed the 'bone accretion rate' (Bauer, Carlsson, and Lindquist, 1955, 1957; Heaney and Whedon, 1958; Fraser, Harrison, and Ibbertson, 1960; Glass and Nordin, 1963). Despite the limitation of such an assumption (Heaney and Whedon, 1958) these methods provide useful tools for the assessment of bone activity in a variety of clinical conditions (Bauer et al., 1957; Fraser et al., 1960).

In the investigation presented here, the accretion rate was determined as a measure of new bone formation, and the rate of urinary calcium excretion was used to assess the degree of bone destruction in patients with carcinoma of the breast, multiple myelomatosis, and Paget's disease of bone. The patients were maintained on a normal hospital diet. 
METHODS

SELECTION OF PATIENTS Six patients with primary malignant tumours who were otherwise in good health and without evidence of bone disease were selected for the control group. Twenty patients with carcinoma of the breast were investigated of whom 14 had radiographic evidence of bone metastases. The latter patients had previously received a variety of treatments including steroids, radiotherapy or adrenalectomy, but at the time of investigation were in relapse. Five patients with Paget's disease of bone and 14 patients with multiple myelomatosis who had skeletal deposits as well as characteristic bone-marrow and plasma protein changes were also investigated.

TECHNIQUe USING ${ }^{45} \mathrm{CALCIUM}{ }^{45} \mathrm{Ca}$ as $\mathrm{CaCl}_{2}, 25$ to $50 \mu \mathrm{c}$., was diluted with $10 \mathrm{ml}$. of $0.9 \%$ saline, sterilized, and injected intravenously. The volume of the injected dose was determined by weighing the container before and after charging the syringe, and by radioassay of syringe residues.

Excreta were collected for 10 to 14 days after the administration of the dose. Urine was passed into 2.5 litre Winchester bottles containing $10 \mathrm{ml}$. concentrated $\mathrm{HCl}$; faeces were wrapped in polythene sheeting and placed in waxed containers. The volume of each $24-\mathrm{hr}$. urine sample was measured and an aliquot (usually $50 \mathrm{ml}$.) was concentrated by wet-ashing with $10 \mathrm{ml}$. fuming nitric acid. A few drops of hydrogen peroxide were added when the ashing was almost complete to prevent charring of the sample. The white precipitate was dissolved in $2 \mathrm{ml}$. of $2 \mathrm{~N} \mathrm{HCl}$ and made up to $10 \mathrm{ml}$. with distilled water. Faecal samples were ashed for 12 hours in a muffle furnace at $600^{\circ} \mathrm{C}$. The ash was weighed and a known aliquot (about 0.1 g.) dissolved in $2 \mathrm{~N} \mathrm{HCl}$ and made up to $100 \mathrm{ml}$. Of these solutions, $1 \mathrm{ml}$. aliquots were adjusted to $p \mathrm{H} 5$ with $25 \%$ ammonia, the calcium precipitated with saturated ammonium oxalate and estimated by titrating with potassium permanganate (Clark and Collip, 1925). Further aliquots of the solutions containing 3 to $4 \mathrm{mg}$. calcium were then pipetted on to $1 \mathrm{~cm} .{ }^{2}$ plastic planchettes fitted into specially constructed perspex centrifuge tubes. Four ml. of a solution containing $1 \mathrm{mg}$. of $\mathrm{Ca} / \mathrm{ml}$. was added to a suitable aliquot of syringe washings and to standard solutions of ${ }^{45} \mathrm{Ca}$. These were treated in the same way as the test samples. After standing overnight the tubes were centrifuged at 2,000 r.p.m. for 20 minutes. The supernatant fluid was decanted and the plastic planchettes were removed and dried at room temperature.

All samples were assayed for radioactivity with a thin end-window GM tube and conventional scaler.

TECHNIQUe USING 35 To $40 \mu \mathrm{C} .{ }^{47} \mathrm{CALCIUM}$ The dose was prepared and administered, and the excreta collected as for ${ }^{45} \mathrm{Ca}$. In some cases $20 \mathrm{ml}$. samples of blood were collected at intervals during the first 24 hours.

The excreta were counted directly after dilution to constant volume by placing the Winchester bottle within a ring of $16 \mathrm{GM}$ tubes. Two standard solutions were prepared each containing $5 \%$ of the dose, one in 2.5 litres of water in a Winchester bottle and the second irwa wax carton containing cotton wool. A lead filter $2 \mathrm{mP}$. thick was placed between the specimen and the GM tubs to avoid recording the radiations from ${ }^{47} \mathrm{Scandium}$ whieh is a daughter isotope of ${ }^{47} \mathrm{Ca}$ and a weak emitter. Figy $\mathrm{ml}$. aliquots of urine were wet-ashed and the calciw⿳⺈ estimated as above. Blood samples were centrifuged añ the calcium was precipitated from $10 \mathrm{ml}$. of plasma with an equal volume of saturated ammonium oxalate. Affer washing with $2 \%$ ammonia the precipitate was dissolved in $2 \mathrm{~N} \mathrm{HCl}$ for radioassay in a well-type scintillation counter. A standard sample was prepared from a suitable aliquot of the injected solution. The ${ }^{47} \mathrm{Ca}$ was assayed $\bar{c}$ 的 an E.H.T. voltage and discriminator bias such as 90 avoid recording activity from ${ }^{47}$ Scandium. The calciogm content of each plasma sample was determined hy permanganate titration after the radioassay.

TECHNIQUE USING 1 to $5 \mu \mathrm{C} .{ }^{47} \mathrm{CALCIUM}$ Excreta wePe collected as above. The volume of each urine specinf?n was measured and $20 \mathrm{ml}$. wet-ashed and made up to $10 \mathrm{ml}$. for calcium estimation as described for ${ }^{45} \mathrm{Ca}$. The remainder of the specimen was evaporated to a small volume and made up to $300 \mathrm{ml}$. Faecal samples wêre ashed in a muffle furnace, dissolved in hot dilute $H \overline{\mathrm{E}} \mathrm{l}$, and made up to $300 \mathrm{ml}$. A standard solution of ${ }^{47} \mathrm{Ga}$ containing a known fraction of the dose was preparedgh a similar volume. Samples were assayed by placing each bottle between two scintillation probes constructed with $7 \times 5 \mathrm{~cm}$. NaI (T1) crystals mounted in a low ba留ground room (Trott, Parnell, Hodt, and Entwistle, 19ङ్ర) and the activity of energy above $300 \mathrm{Kev}$. recorded.

CALCULATION OF THE RATE OF CALCIUM ACCRETION IN BONE Specific activities of urine were expressed as percent per milligram dose of calcium. Preliminary studies of both blood and urine specimens showed that the mean specific activity of a sample of urine was similar to that of.a sample of plasma obtained after an interval of time eqस्al to one third of the period in which the urine was collected. Thus the mean specific activity of a 24-hour urine approximated that of a sample of plasma obtained eight hours after the start of the urine collection. Owing to the small doses of ${ }^{47} \mathrm{Ca}$ used and its short half-life (4.7 da $\mathrm{x}$ ) low activities were present in the plasma; thus ge measurement of the mean urinary specific activity obviated the use of large volumes of plasma. The spectic activity of plasma calcium, whether measured directly deduced from the urine data, was adjusted for losseson the excreta by dividing the observed specific activity by the fraction of the dose retained in the body at that time (Fig. 1). The adjusted specific activity values were plotted on semi-logarithmic paper. A curve was obtained for exh investigation which could be analysed into a numberof exponential functions. The early mixing componefts were ignored for these purposes and the last linear part of the curve was assumed to represent the rate at which calcium was lost from the extracellular fluid into segipermanent or permanent bone. The percentage dose retained in the body plotted semi-logarithmically show $\mathrm{S}$ deviation from linearity in the early part of the cusfe resulting from a disproportionate loss of activity in the 


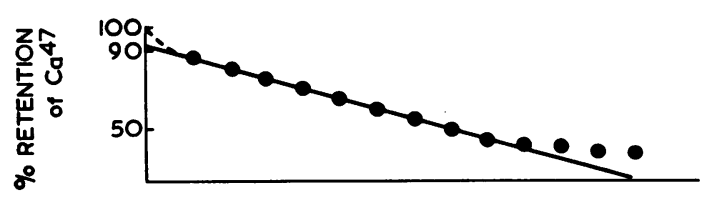

TABLE I

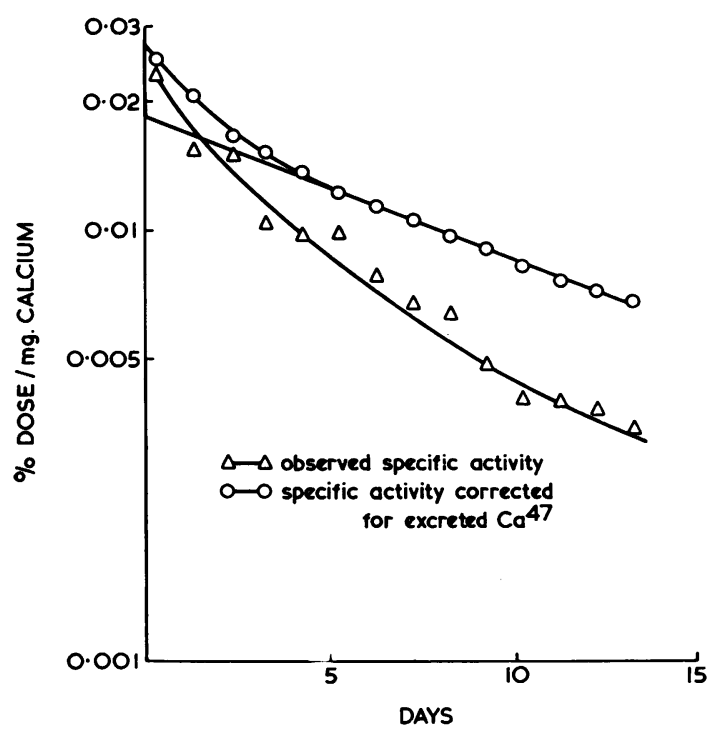

FIG. 1. Example of retention of dose of radioactive calcium and alterations in specific activity of calcium corrected for excreted losses.

urine during the early mixing phases (Fig. 1). The percentage dose retained at zero time obtained by extrapolating the linear part of this curve was used in the following calculations.

1 Exchangeable calcium pool (mg.) =

Extrapolated percentage retained at zero time

Extrapolated specific activity at zero time

2 Rate constant (fraction/day) $=$ 0.693

Half-time of linear part of specific activity curve (days)

3 Accretion rate (mg. $\mathrm{Ca} /$ hour) $=$

Exchangeable pool size $\times$ rate constant

24

RESULTS

The values for the exchangeable calcium pool, the calcium accretion rate, and the mean 24-hourly urinary calcium excretion are given in Table I. The six control patients had a mean accretion rate of $24.8 \pm 7.7$ (S.D.) mg./hr. Although the mean value of $16.7 \pm 10.2 \mathrm{mg}$./hr. for patients with carcinoma of the breast without metastases was lower, this

difference was not statistically significant $(0 \cdot 1<p<$ $0 \cdot 2$ ). Patients with bone metastases showed an increase in the accretion rate with a mean value of $45.2 \pm 27.9 \mathrm{mg}$. $/ \mathrm{hr}$. but only the group of patients who excreted more than $300 \mathrm{mg}$. of calcium in 24 hours showed an increase in accretion rate, i.e., $50.3 \pm 24.6 \mathrm{mg}$./hr. which was significantly higher than the control value $(0.02<p<0.05)$.

The mean accretion rate for the patients with 
TABLE II

RATES OF BONE ACCRETION AND OF URINARY EXCRETION OF CALCIUM IN PATIENTS WITH CARCINOMA OF BREAST, MULTIPLE MYELOMATOSIS, AND PAGET'S DISEASE

\begin{tabular}{lr} 
Group \\
\\
\hline Control \\
Carcinoma of breast without bone metastases \\
Carcinoma of breast with bone metastases \\
(a) All cases \\
(b) Cases with urinary excretion $>300 \mathrm{mg} /$ day \\
Multiple myelomatosis \\
Paget's disease
\end{tabular}

multiple myelomatosis, $35.7 \pm 11.4 \mathrm{mg}$./hr., was somewhat higher than that for the controls $(\mathrm{p}=$ 0.05). However, the group of patients with Paget's disease of bone showed a very great increase in accretion rate, the mean being $118.1 \pm 68.0 \mathrm{mg}$. $/ \mathrm{hr}$. (p < 0.01) (Table II).

The mean urinary calcium excretion rate of control patients on an unrestricted diet was found to be $207.0 \pm 51.0 \mathrm{mg}$. $/ 24 \mathrm{hr}$. (Table II). Patients with carcinoma of the breast showed an increased urinary calcium excretion rate, particularly those with bone metastases whose mean rate was $277.4 \pm 162.8$ mg. $/ 24 \mathrm{hr}$. The patients with multiple myelomatosis showed the greatest rate of urinary calcium excretion, the mean value being $287.5 \pm 133.5 \mathrm{mg}$. $/ 24 \mathrm{hr}$. The

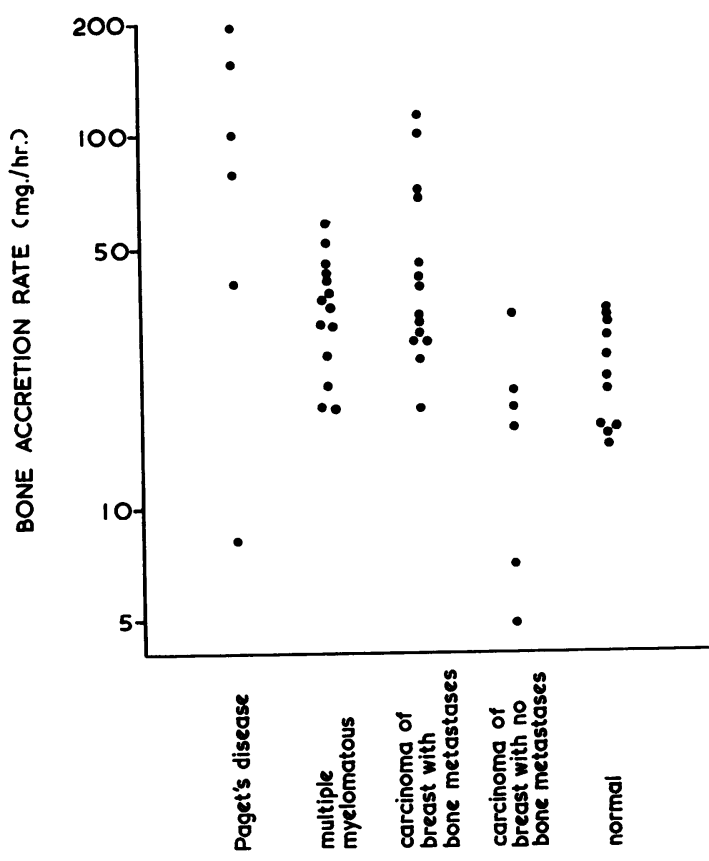

FIG. 2. Distribution of values of accretion rate in carcinoma of breast, multiple myelomatosis, and Paget's disease of bone.

\begin{tabular}{l} 
Mean Bone Acr \\
Rate (mg./hr. \\
S.D.) \\
\hline $24 \cdot 8 \pm 7 \cdot 7$ \\
$16 \cdot 7 \pm 10 \cdot 2$ \\
\\
$45 \cdot 2 \pm 27 \cdot 9$ \\
$50 \cdot 3 \pm 24 \cdot 6$ \\
$35 \cdot 7 \pm 11 \cdot 4$ \\
$118 \cdot 1 \pm 68 \cdot 0$
\end{tabular}

excretion rate in the group of patients with Page disease was $112.2 \pm 47.6 \mathrm{mg}$. $/ 24 \mathrm{hr}$.

\section{DISCUSSION}

Among the patients with carcinoma of the breast studied those who had bone metastases and excreted more than $300 \mathrm{mg}$. of calcium in 24 hours showed the highest accretion rates (Table II). In contrast, of the six patients without evidence of bone metastase four had normal and two had unusually low accretion rates. Only two of the patients in this grow excreted more than $300 \mathrm{mg}$. calcium in 24 hours. Similar low accretion rates have been reported patients with idiopathic or post-menopausal osteporosis (Nordin, 1961; Glass and Nordin, 1963. Although the number of patients in this group small our findings suggest that in a proportion \&f patients with carcinoma of the breast without bone metastases there may be an increased breakdown gf bone without a compensatory increase in boge growth.

The accretion rate obtained for one of the patients with carcinoma of the breast and bone metastases was $112 \mathrm{mg}$. $/ \mathrm{hr}$., or 2.4 standard deviations high $8 \mathrm{gr}$ than the mean for the whole of this group of patients (Table II). If this patient is excluded from the gro@ a significant correlation is seen between the rates of accretion and of urinary calcium excretion (coitrelation coefficient $=0.623 ; P=0.02$ ). This suggesiss that increased new bone formation may be asso $\mathrm{E}-$ ated with osteolytic secondary deposits.

In contrast, in patients with multiple myeloma, there was no correlation between excretion a ged accretion rates, suggesting that the process of new bone formation in this condition is not dependent that of bone destruction. The isotope investigations were repeated after radiotherapy in three of the patients in this group (Table III). Reductions : in accretion rates were noted in all three patients. ThMs may have been due to damage to osteoblasts in the irradiated bone, but in view of the local nature of the treatment it is more likely that it reflects the naturi 1 history of the disease. 
TABLE III

REPEATED OBSERVATIONS ON THREE PATIENTS WITH MULTIPLE MYELOMATOSIS

\begin{tabular}{llll} 
Patient & Observation & $\begin{array}{l}\text { Accretion Rate } \\
(\mathrm{mg} . / \mathrm{hr} .)\end{array}$ & $\begin{array}{l}\text { Mean Urinary } \\
\text { Calcium } \\
(\text { mg./24 hr. })\end{array}$ \\
\hline 1 & 1 & $25 \cdot 7$ & 374 \\
& 2 & $23 \cdot 8$ & 161 \\
5 & 3 & $19 \cdot 9$ & 314 \\
& 1 & $35 \cdot 2$ & 431 \\
10 & 2 & $32 \cdot 0$ & 386 \\
& 1 & $41 \cdot 0$ & 383 \\
& 2 & $15 \cdot 8$ & 409
\end{tabular}

The high values of accretion rate observed in the patients with Paget's disease of bone are associated with relatively low excretion of calcium in the urine (Table II). Previous observations of accretion rate in patients with Paget's disease have shown similar high values and they probably reflect the great activity in calcium turnover in the affected bone (Heaney and Whedon, 1958; Bauer et al., 1961).

Our findings provide some confirmation for the conclusions derived from the earlier observations of the changes in the levels of serum alkaline phosphatase. Woodard (1953) observed raised levels of alkaline phosphatase in about half of her cases of carcinoma of the breast with metastatic bone disease. She also observed that a rise in serum alkaline phosphatase was less common in multiple myelomatosis, and indeed the level of this enzyme was often reduced. Thus by measuring the urinary calcium excretion and the bone accretion rate of calcium by isotope techniques a useful assessment can be made of the rate of calcification of newly formed bone relative to the degree of bone destruction.

We wish to thank Dr. N. G. Trott and other members of the Physics Department of the Institute of Cancer Research for their advice and help with many technical problems.

We are considerably indebted to Professor D. W. Smithers, in whose department this work was undertaken, for his encouragement and for many valuable discussions of the clinical implications of our work.

\section{REFERENCES}

Bauer, G. C. H., Carlsson, A., and Lindquist, B. (1955). K. fysiogr. Sällsk. Lund Förh., 25, 1

,,--- (1957). Acta med. scand., 158, 143

- - (1961). Mineral Metabolism, edited by C. L. Comar and F. Bronner, vol. 1, pt. B, p. 663. Academic Press, New York and London.

Clark, E. P., and Collip, J. B. (1925). J biol Chem, 63, 461.

Fraser, R., Harrison, M., and Ibbertson, K. (1960). Quart. J. Med., 29. 85.

Glass, H. I., and Nordin, B. E. C. (1963). Phys. in Med. Biol., 8, 387.

Gutman, A. B., Tyson, T. L., and Gutman, E. B. (1936). Arch. intern. Med., 57, 379.

Heaney, R. P., and Whedon, G. D. (1958). J. clin. Endocr., 18, 1246.

Laszlo, D., Schulman, C. A., Bellin, J., Gottesman, E. D., and Schilling, A. (1952). J. Amer. med. Ass., 148, 1027

Nordin, B. E. C. (1961). Lancet, 1, 1011

Spencer, H., Laszlo, D., and Brothers, M. (1957). J. clin. Invest., 36, 680.

Trott, N. G., Parnell, C. J., Hodt, H. J., and Entwistle, R. F. (1963). Brit. J. Radiol., 36, 592.

Woodard, H. Q. (1953). Cancer (Philad.), 6, 1219. 